Im „Journal Club" werden Originalarbeiten aus der internationalen Fachliteratur referiert und kommentiert.

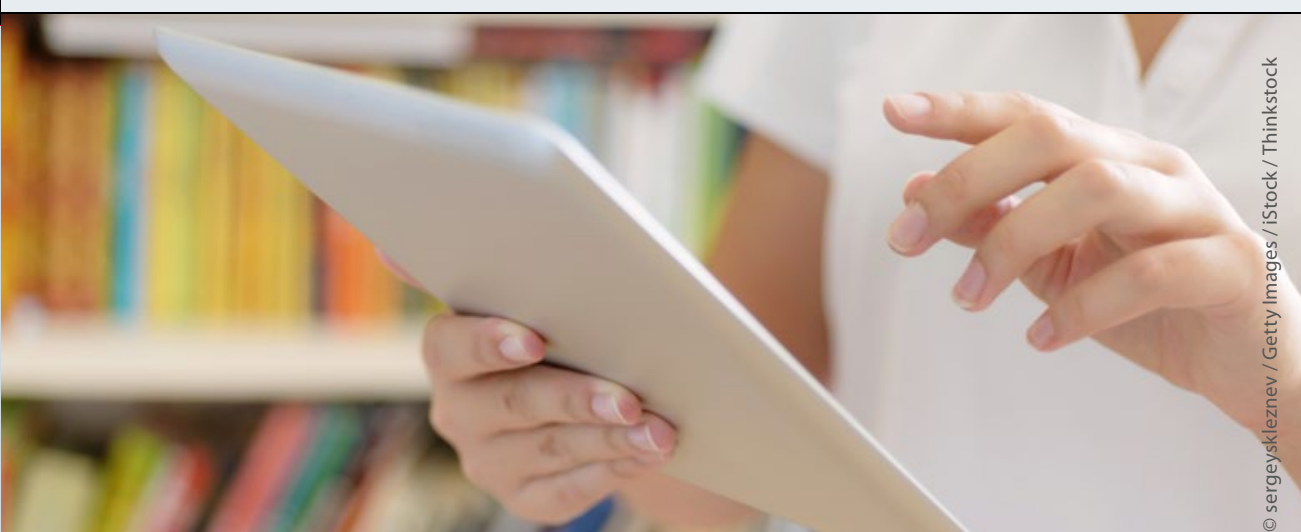

\section{Und wenn die rote Linie das Herz erreicht?}

\section{Ein 23-jähriger Mann suchte wegen zunehmender Schmerzen und Rötung} am linken Arm die Nothilfe auf. Am Abend zuvor hatte er sich beim LacrosseSpiel am dritten Finger links verletzt.

$\mathrm{D}$ ie Schmerzen hatten in der Nacht begonnen. Die Temperatur bei Aufnahme lag bei $36,7^{\circ} \mathrm{C}$, die Herzfrequenz

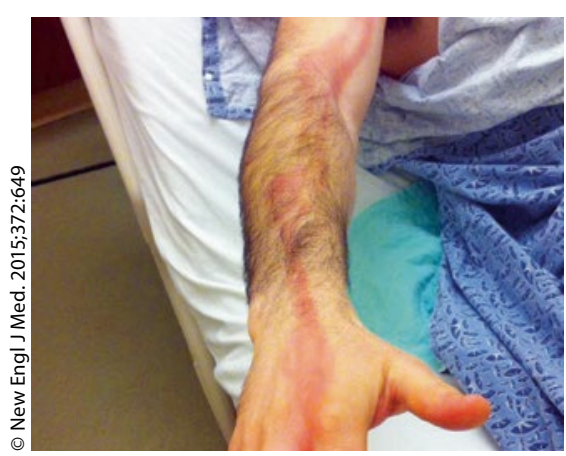

bei 64/min. Der Blutdruck betrug 139/85 mmHg. Am Endglied des geröteten und druckschmerzhaften dritten Fingers links war eine Blase oder ein Abszess zu sehen. Außerdem erstreckte sich eine streifenförmige Rötung bis zum Ellenbogen. Innerhalb weniger Stunden hatte sich dieser Streifen bis in die Axillarregion ausgedehnt.

Der Abszess wurde inzidiert und drainiert. Man begann eine kalkulierte antibiotische Therapie mit Cefazolin und Vancomycin. Kulturell konnte Streptococcus pyogenes angezüchtet werden, worauf das antibiotische Regime auf Penicillin $\mathrm{G}$ i. v. umgestellt wurde. Am zweiten Tag war die Rötung zurückgegangen, und der Patient wurde unter einer Therapie mit oralem Penicillin V entlassen. Eine Woche nach Entlassung waren das Erythem und die Schmerzen deutlich zurückgegangen. Als Kinder nannten wir so etwas "Blutvergiftung“ und hatten mächtig Angst davor.

MMW - Fortschritte der Medizin 2015/14 basierend auf: Vindenes T, McQuillen D. Acute Lymphangitis. New Engl J Med. 2015;372:649

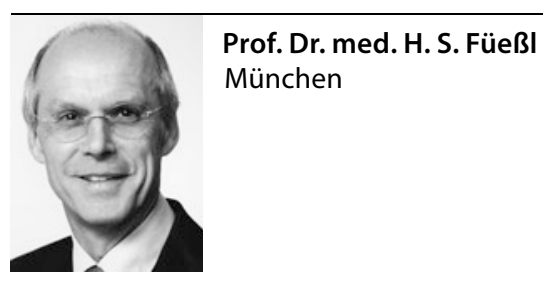

\section{Gute Zusammenarbeit verbessert Versorgungsqualität von Heimbewohnern}

\section{An der Versorgung von Altenpflegeheimbewohnern sind tagtäglich verschie- dene Berufsgruppen beteiligt, von denen Pflegende und Ärzte in besonde- rem Maß auf eine gute Kooperation angewiesen sind. Wie gut das Zusammenwirken der beiden Berufsgruppen aber tatsächlich ist, stand nun im Fokus einer Studie in Heidelberg.}

D ie Betreuung kranker, alter und hochaltriger Menschen in stationären Pflegeeinrichtungen stellt Pflegende und Ärzte im aktuellen Kontext vor multiple Herausforderungen. Die Gewährleistung einer guten Versorgungsund Lebensqualität für die Bewohner hängt von vielen Faktoren, z.B. der Um- setzung eines adäquaten Zeit- und Personalmanagements ab. Vor allem der Zusammenarbeit im interdisziplinären Team kommt eine Schlüsselfunktion und damit hohe Bedeutung zu.

Für die Studie wurden 172 professionell Pflegende sowie 83 beteiligte Hausund Fachärzte in 14 Pflegeheimen mit- hilfe einer standardisierten Fragebogenerhebung zu wahrgenommenen Problemen und Möglichkeiten zu Verbesserungen in der Zusammenarbeit mit der jeweils anderen Berufsgruppe befragt. Erwartungshaltungen sollten offengelegt; Ressourcen und Probleme benannt werden. So bemängelten Ärzte eine teils unflexible und nichttransparente Aufgabenwahrnehmung, fachliche Überforderung und mangelhafte Kommunikationsstrukturen, wie das Fehlen fester Ansprechpartner beim Pflegepersonal. Pflegende hingegen beklagten, dass sie im Umgang mit Ärzten oft keine Zusammenarbeit auf Augenhöhe erfahren. Sie wünschten sich einen konstruktiveren und effektiveren Informationsaustausch, eine höhere gerontopsy- 